\title{
Orchard Laborer Dies after Being Struck and Run Over by Dump Trailer
}
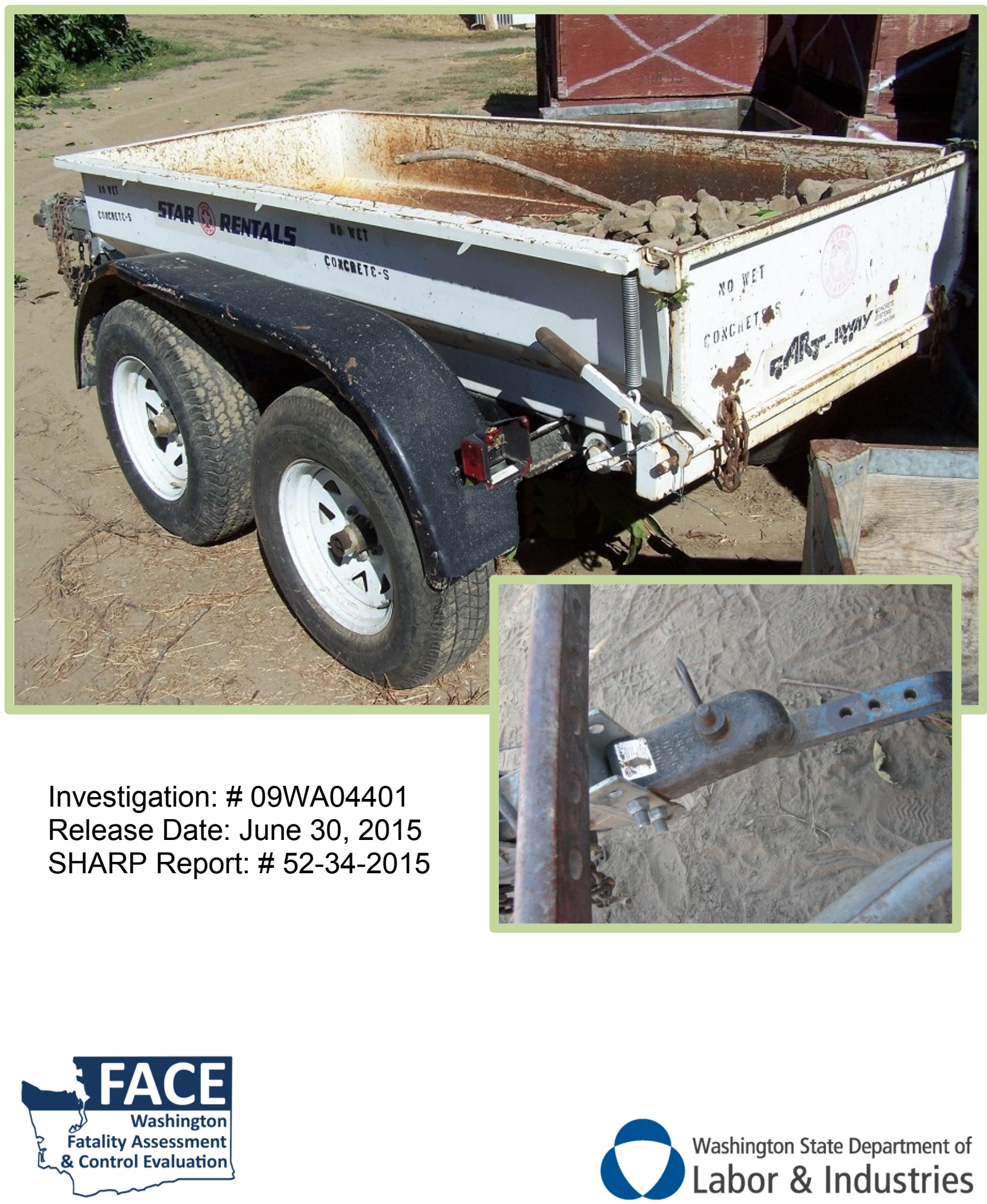

Washington State Department of Labor \& Industries 


\section{TABLE OF CONTENTS}

CONTENTS

DEFINITIONS

SUMMARY

4

RECOMMENDATIONS

INTRODUCTION

Employer 5

Employer work organization 5

Employer safety training program

Victim

Tractor and trailer

Procedure for connecting trailer

Safety chains

Tractor operator

Incident scene

INVESTIGATION

CONTRIBUTING FACTORS

CAUSE OF DEATH

RECOMMENDATIONS AND DISCUSSION

ACKNOWLEGEMENTS

REFERENCES

INVESTIGATOR INFORMATION

FACE PRORGRAM INFORMATION 


\section{DEFINITIONS}

$\begin{array}{ll}\text { APP } & \text { Accident Prevention Program } \\ \text { DOSH } & \text { Division of Occupational Safety and Health } \\ \text { EMS } & \text { Emergency Medical Services } \\ \text { FACE } & \text { Fatality Assessment and Control Evaluation } \\ \text { NIOSH } & \text { National Institute for Occupational Safety and Health } \\ \text { SHARP } & \text { Safety and Health Assessment and Research for Prevention } \\ \text { SOP } & \text { Standard Operating Procedure } \\ \text { WA } & \text { Washington State } \\ \text { WISHA } & \text { Washington Industrial Safety and Health Act }\end{array}$




\section{SUMMARY}

On September 17, 2009 a 49-year-old orchard worker was fatally injured when he was struck and run over by a dump trailer that became unhitched from a tractor. At the time of the incident, the operator of the tractor was pulling the trailer up the side of a rough, steep dirt orchard road. The victim and another worker were loading the trailer with rocks that were excavated from the orchard rows. The victim went behind the trailer, as it was moving, to pick up rocks from the ground. The tractor started to lose traction, causing the trailer to hop. The hopping motion caused the trailer coupler to unhitch from the trailer hitch ball. The trailer rolled down the sloped road, and struck and ran over the victim. Emergency medical services were contacted and arrived on the scene. The victim was transported to the hospital where he was put on life support. Approximately two days after being admitted the victim was taken off life support and passed away. Following the incident, investigators noted that the trailer hitch ball on the tractor was not the proper size for the trailer coupler, and the safety chains and other safety equipment were not properly connected or not functioning.

To prevent similar incidents Washington State Fatality and Control Evaluation (FACE) recommends that:

Employers:

- Develop a system to match trailer hitch balls and trailer couplers by size and to ensure that each tractor-trailer combination has the necessary safety equipment.

- Develop and enforce policies requiring tractor operators to properly connect, inspect, and maintain safety systems before towing a trailer or other equipment.

- Train tractor operators and workers on foot on how to:

- Identify hazards associated with working behind vehicles, trailers, and other equipment being towed on slopes.

- Properly use safety systems and to follow safety policies and procedures. 


\section{INTRODUCTION}

On September 28, 2009, the Washington State Fatality Assessment and Control Evaluation (FACE) program was notified by Washington State's Division of Occupational Safety and Health (DOSH) of the death of a 49-year-old orchard worker.

After reviewing the DOSH investigation report, Washington State FACE investigators interviewed the owner of the orchard. During the meeting, the owner provided information regarding the history, organization, and health and safety programs of the orchard, as well as insight into circumstances surrounding the incident. In the course of the investigation, documents reviewed included the police report, the coroner's report, and DOSH investigation documents and photographs.

\section{Employer}

The employer has been in the apple and cherry orchard business since the early 1980s and at the time of the incident employed four full-time employees year-round and had one part-time employee (the victim) who worked on an as needed basis. During the harvest season, from June to August, the employer has up to 120 part-time employees. The rest of the year, part-time workers are employed on an as-needed basis. According to the employer, nearly all of workers hired by the orchard speak Spanish as their primary language.

\section{Employer Work Organization}

The employer oversees the orchard's daily operations, and acts as the safety manager. The orchard employs crew leaders, pickers, laborers and machinery operators during the harvest season. The four full-time employees have the job title of "crew leader." Crew leaders are responsible for supervising a crew of pickers and laborers. Pickers are responsible for picking the cherries. Approximately $90 \%$ of workers are classified as pickers during harvest season. Laborers complete other tasks that are needed, such as clearing debris from orchard rows. The orchard employs approximately six laborers and eight machinery operators during harvest season. Machinery operators at the orchard use low profile tractors, sprayers, and forklifts. The orchard employs a worker who is responsible for completing monthly inspections on machinery, buildings, and storage areas to ensure that they are in proper and safe working order. 


\section{Employer Safety and Training Program}

The employer has a comprehensive Accident Prevention Program (APP) that is written in English. According to the DOSH inspection, the APP meets Washington Industrial Safety and Health Act (WISHA) standards. The employer holds monthly safety meetings conducted in English and Spanish, with written material provided in both languages. Safety meeting topics are based on the season, so that the most relevant topics for that time of year are discussed. For example, trailer safety is discussed annually just before harvest season, when trailers are used most frequently.

All new employees participate in orientation training. After the orientation training, workers receive specialized training based on their job duties. For example, pickers are trained in ladder safety and machinery operators get safety training on the machines they will be using. Machinery operators are only hired if they have previous experience and can demonstrate safe operating skills. As part of the training for tractor use, operators are taught to do a walk around inspection of the tractor before operating it.

At least once annually, the employer provides all employees with training on how to properly connect tractors and trailers and work safely on foot around trailers. Other annual safety trainings include saw safety for pruning, and ladder safety.

\section{Victim}

The victim was born in Mexico and was hired by the employer in 1991. The victim worked as both a part-time and full-time employee during his tenure, but had spent more time working as a part-time employee. At the time of the incident, the victim was working year round as a part-time laborer. According to the employer, the victim was very familiar with the orchard, as he had helped to plant many of the orchard's trees. The victim completed whatever work needed to be done. The victim typically cleared brush in the winter; did bloom thinning and tree training in the spring; and worked where needed during harvest season, including being a picker or occasional crew leader. The employer stated that the victim never operated machinery, because he was not trained to do so. According to the employer the victim had previously loaded rocks into the dump trailer but didn't know when he had last completed the task.

\section{Tractor and Trailer}

The tractor was a mid-1980s low profile Ford, model number 3910 which had been purchased used. The tractor had been previously used to tow the trailer involved in the incident. The trailer was a 1988 Cart-Away 2-axle construction dump trailer equipped 
with surge brakes and a safety break away cable actuated brake. It was purchased by the employer from a rental company two years before the incident, but did not include the safety manual.

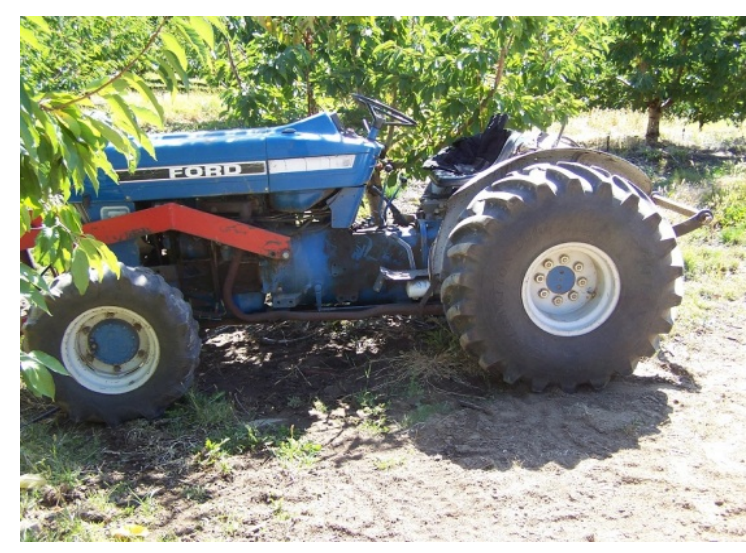

Photo 1. Ford model tractor that was involved in incident

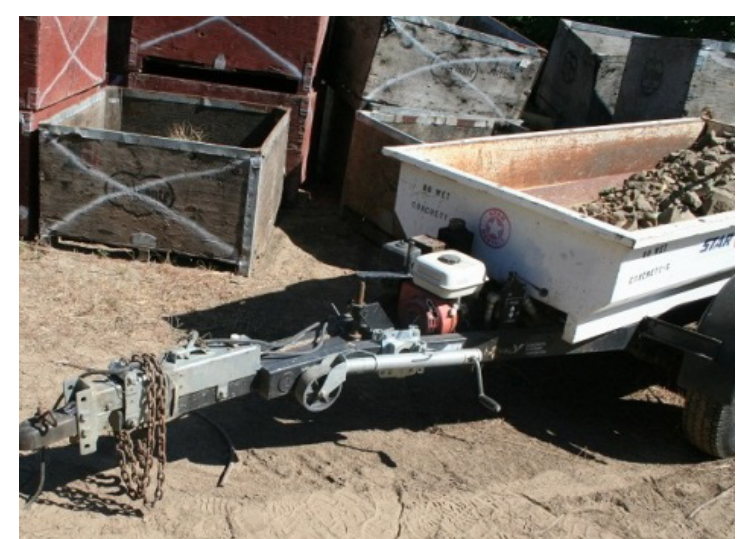

Photo 2. Construction dump trailer involved in incident

\section{Procedure for Connecting the tractor and Trailer}

The tractor was equipped with a bumper pull hitch. This allows the trailer hitch ball to be changed without unhooking it from the tractor. It also allows multiple trailer hitch balls to be connected at one time. The orchard kept all trailer hitches in one location. The trailer was equipped with a coupler that used a screw type latching mechanism to secure the coupler to a hitch ball. The coupler was a fixed size and not interchangeable.

At the time of the incident the tractor had a 2 inch trailer hitch ball mounted on the bumper pull hitch while the trailer coupler was $2^{5 / 16}$ inch. This was the only orchard dump trailer with a coupler that required a $2^{5 / 16}$ inch trailer hitch; all other trailers required a 2 inch trailer hitch ball. The trailer was used on an as needed basis for the orchard approximately $2-3$ times per year. According to the employer, the trailer most likely would not have come unhitched if the tractor was pulling it on level ground, as the difference in the ball sizes was only $5 / 16$ th of an inch.

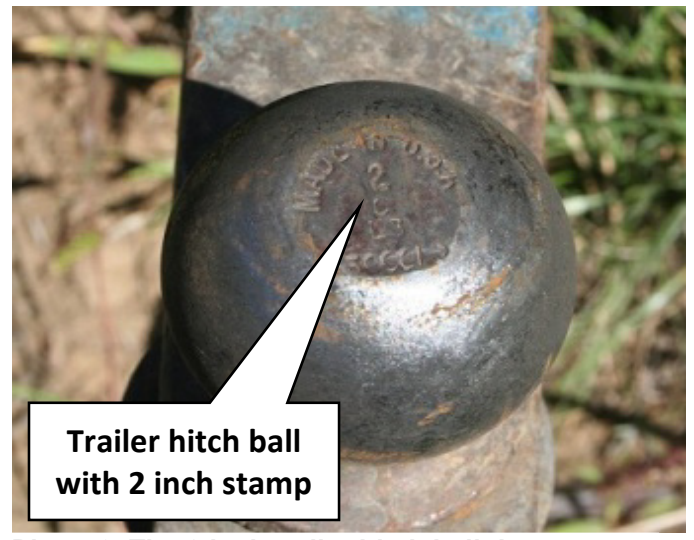

Photo 3. The 2 inch trailer hitch ball that was mounted on the bumper pull hitch and connected to the trailer coupler

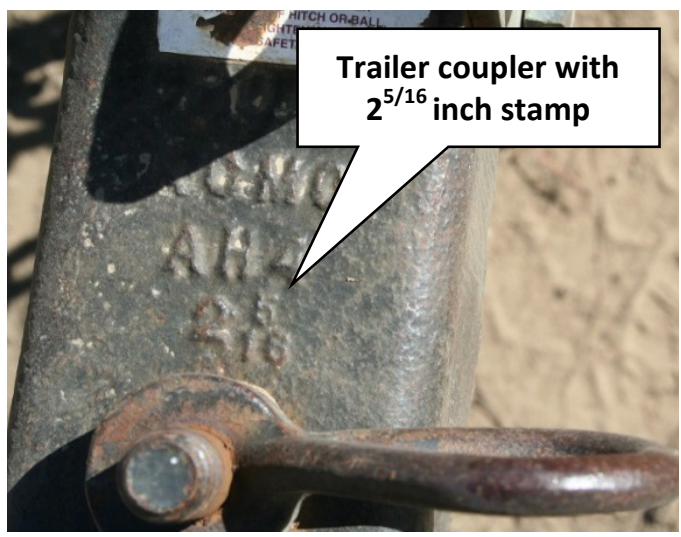

Photo 4. Trailer coupler and screw used to tighten to trailer hitch ball 
Tractor operators were responsible for:

- Ensuring that the trailer had the proper hitch and that it was connected properly.

- Checking to ensure the trailer was hitched properly if someone other than the operator connected the trailer.

- Lifting up on the trailer's tongue to ensure that the trailer was connected properly to the hitch.

- Wrapping safety chains around the adjustable stabilizer arms and hooking into a link on the chains.

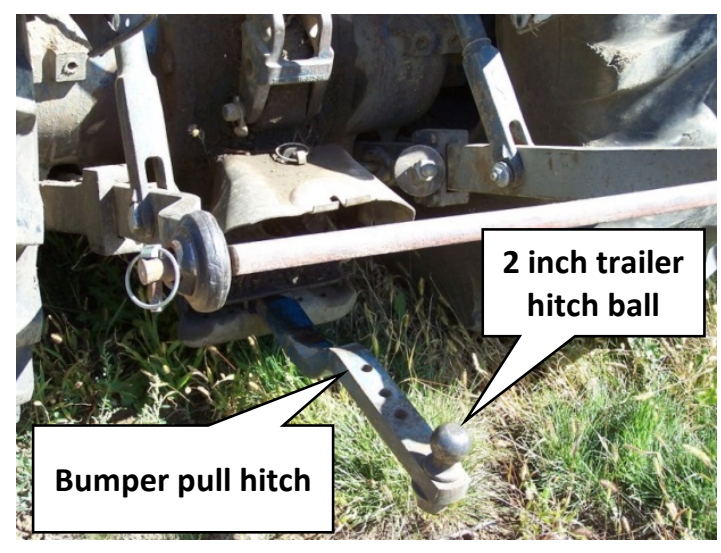

Photo 5. Back of tractor involved in incident, showing the bumper hitch and the attached 2 inch trailer hitch ball

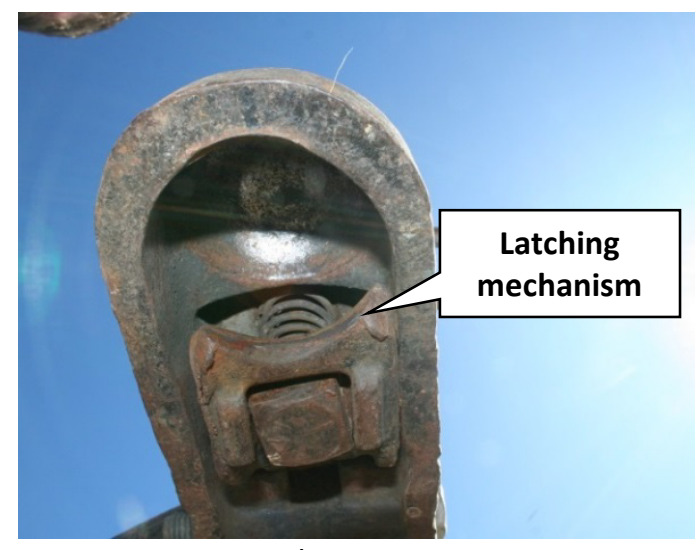

Photo 6. Inside of $2^{5 / 16}$ inch trailer coupler showing latching mechanism and screw used to secure coupler to trailer hitch ball

\section{Safety Chains}

Safety chains are intended to prevent the trailer from detaching from the tractor if the trailer becomes unhitched from the hitch. The orchard's standard operating procedure (SOP) was to wrap the safety chains around the adjustable stabilizer arms and then slip-fit the hook on the end of the safety chains into the links (photo 7).

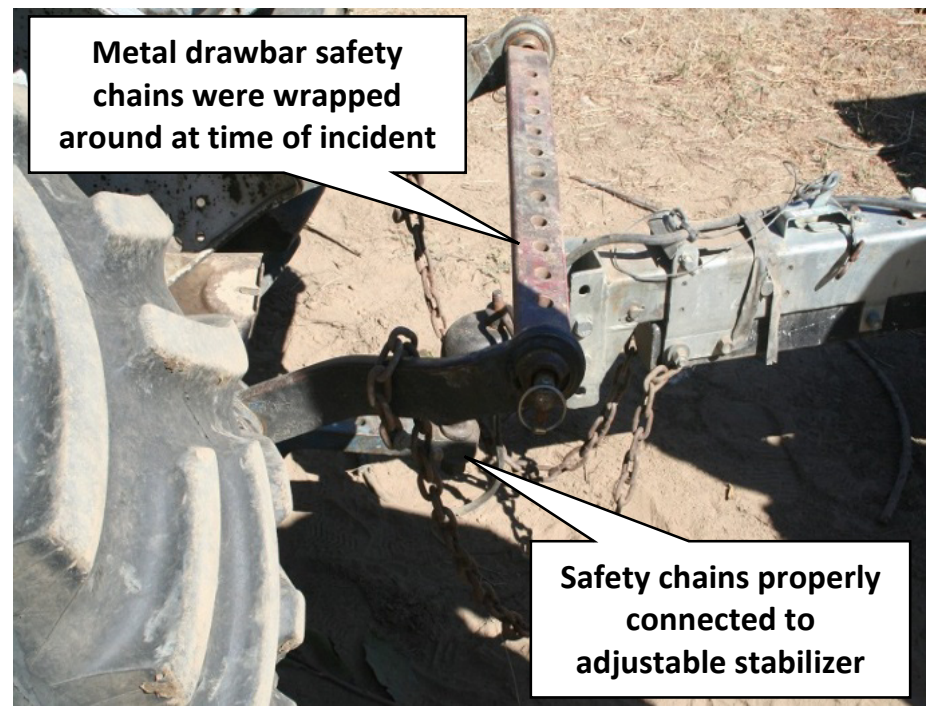

Photo 7. Example of employer's procedure for properly connecting safety chains to stabilizer arms, not the metal drawbar. 


\section{Tractor Operator}

According to the employer, the tractor operator supervised the orchard when the employer was not on site. Prior to his employment at the orchard, the tractor operator had experience driving low profile tractors. At the orchard, the tractor operator used the Ford low profile tractor to tow the trailer involved in the incident several times. It was considered a normal job duty. The tractor operator had participated in the employers training on how to properly attach the trailer to the tractor.

\section{Incident Scene}

The orchard road where the incident occurred was made up of packed ground and had a steep incline. According to the police report, the weather was warm, clear, and dry. The employer did not believe any environmental issues were a factor in the incident.

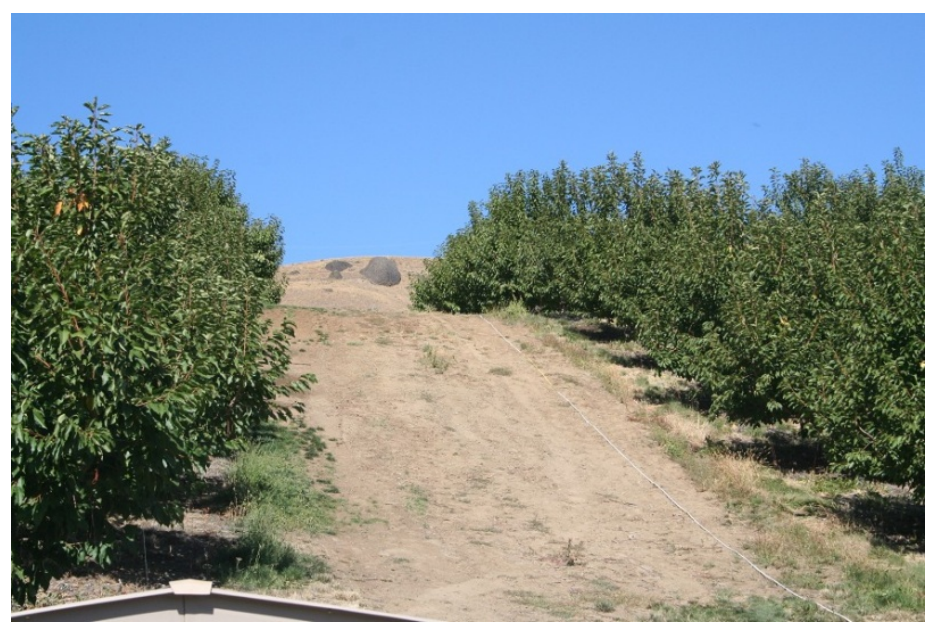

Photo 8. View looking up the orchard road showing approximate where the trailer became unhitched from the tractor.

\section{INVESTIGATION}

At approximately 9:40 am on September 17, 2009, a three person work crew was clearing rocks from the orchard rows. The laborer (victim) and machinery operator were responsible for picking up rocks and putting them in the back of a dump trailer hitched to a low profile tractor.

The tractor operator was towing the partially full dump trailer up the side of a steep orchard road with the intention of turning the tractor and trailer around. Near the top of the slope, the tractor started to lose traction and the trailer began to hop. The hopping caused the trailer coupler to dislodge from the trailer hitch ball. The victim, who was bent over behind the trailer picking up rocks, was struck and knocked to the ground by the runway trailer. The trailer then dragged him approximately 20 feet. 
The victim's coworker immediately called 911 and then began CPR. The victim was transported to a hospital where he was taken off life support and passed away approximately two days after the incident.

The tractor operator reported that he connected the trailer to the tractor and tightened the screw that clamps the coupler securely to the ball even though the trailer hitch ball was not the correct size for the trailer coupler. None of the workers checked that the trailer coupler was fully secured by attempting to lift the trailer tongue from the trailer hitch ball.

The tractor operator and machinery operator said that they usually hooked the safety chains over the metal drawbar instead of wrapping them around the stabilizer arms and connecting the hook into a chain link. Witnesses agreed, reporting that the tractor operator and a co-worker slid the safety chain hooks over the metal drawbar instead of wrapping them around the stabilizer arms and hooking the ends. This practice created an unsafe condition because the drawbar is capable of fully rotating forwards and backwards. The drawbar may have rotated allowing the chains to detach and the trailer to separate from the tractor and roll down the steep orchard road. It was also noted that the trailer surge brakes and safety break away cable were either not connected or not functioning and consequently could not stop the unhitched trailer.

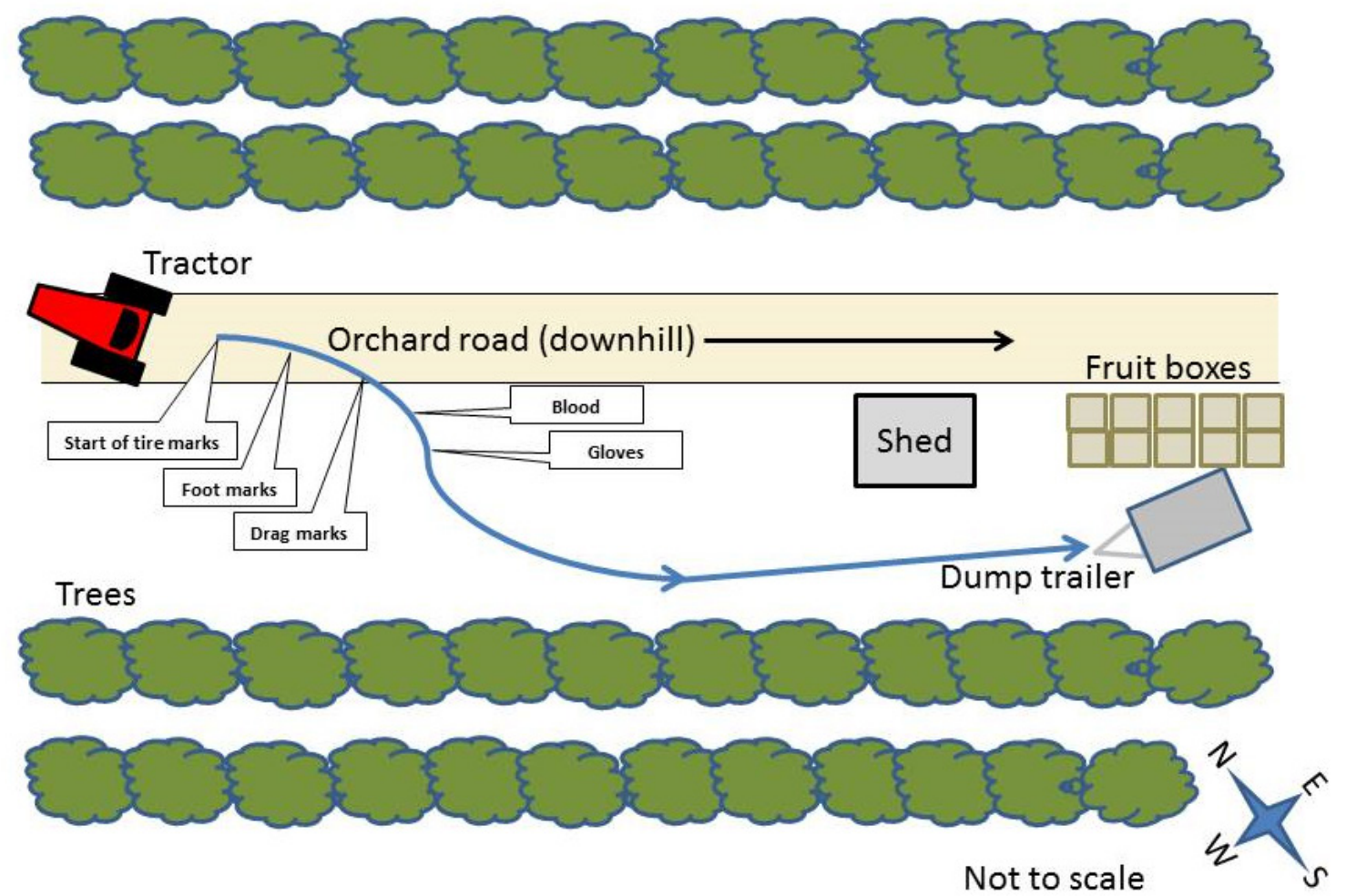

Figure 1. Diagram based on sketch by police officer who responded to call, showing the path the trailer took after becoming unhitched from the tractor. 


\section{CONTRIBUTING FACTORS}

- Trailer hitch ball and coupler sizes did not match.

- Safety chains and other safety equipment were not connected or functioning properly.

- Victim was working behind trailer on a slope.

- Lack of training and enforcement of safety policies and procedures.

\section{CAUSE OF DEATH}

The medical examiner listed the cause of death as depressed skull fracture and cerebral anoxia.

\section{RECOMMENDATIONS AND DISCUSSION}

\section{Recommendation 1: Develop a system to match trailer hitch balls and trailer couplers by size and to ensure that each tractor-trailer combination has the necessary safety equipment.}

\section{Discussion:}

Tractor-trailer couplings should not become unhitched on inclines, curves, or rough terrain. Having an organizational system, clearly labeling hitch ball and coupler sizes, or using other visual reminders to inform workers of the varying sizes could help prevent mismatching trailer hitch balls and couplers.

Prior to purchasing the Cart-Away trailer, all of the employer's trailers required a 2 inch trailer hitch ball. However, the Cart-Away trailer required a $2^{5 / 16}$ inch trailer hitch ball. The coupler being 5/16 of an inch larger than the hitch ball created a situation where the coupler did not stay securely latched. Trailer hitch balls and trailer tongues are stamped with the size of the connection needed, but these can be difficult to see.

One method to eliminate this hazard is to standardize hitch ball and coupler sizes. Other organizational systems to eliminate this hazard include:

- Matching trailer hitch balls and trailer couplers by size with the same color paint.

- Keep the correct size trailer hitch ball in each trailer and install when using.

- Put clear and evident labels on each trailer indicating the size of the trailer hitch required. 
In addition to correctly size-matched hitch balls and couplers, each tractor and trailer should be equipped with properly maintained and connected safety equipment.

Also, employers should consult the operator's manual, if available, for each tractor and trailer to ensure that all hitching processes meet manufacturer recommendations.

\section{Post-Incident Remediation}

Following the incident the employer painted the $2^{5 / 16}$ trailer ball a different color to help alert workers of the size difference.

\section{Recommendation 2: Develop and enforce policies requiring tractor operators to properly connect, inspect, and maintain safety systems before towing a trailer or other equipment.}

\section{Discussion:}

This employer did have an SOP for connecting safety chains but it was not followed. To ensure that tractor operators and other designated workers follow SOPs and properly connect safety chains or other safety systems, employers should use checklists or similar tools to consistently monitor and enforce policies. Examples of procedures for a checklist should include but not be limited to the following

- Checking to ensure that the tractor is the right size for the trailer and load being towed.

- Checking to ensure that the trailer hitch ball is the proper size for the trailer coupler.

- Wiping the hitch ball clean and inspecting visually and by feel for flat spots, cracks, and pits.

- Rocking the ball to make sure it is tight to the hitch, and visually checking that the hitch ball nut is solid against the lock washer and hitch frame.

- Wiping the inside and outside of the coupler clean and inspecting it for cracks and deformations

- Checking to ensure that the safety chains have a proper rating for the implement being towed and are not damaged.

- Connecting the trailer coupler to the trailer ball hitch on the tractor's draw bar.

- Securing the safety pin, lock, or screw to prevent the coupler from dislodging.

- Properly connecting the safety chains to a secure location on the implement hitch and tractor, leaving only enough slack for articulation. 
- Before towing the trailer, checking to ensure that the trailer will not come unhitched. This can be done by:

- Pulling up on the trailer tongue to see if the trailer coupler dislodges from the trailer hitch ball.

- Raising and lowering the drawbar to see if trailer becomes unhitched.

Employers should also develop policies to ensure that other safety equipment including surge brake systems and related safety breakaway cables are functional in order to prevent trailer breakaways. Policies should include SOPs on how frequently systems should be inspected and how they should be tested and maintained.

\section{Recommendation 3: Train tractor operators and workers on foot on how to: \\ - Identify hazards associated with working behind vehicles, trailers, and other equipment being towed on slopes.}

- Properly use safety systems and to follow safety policies and procedures.

\section{Discussion:}

The employer's training program did not contain specific training for workers on how to identify and avoid the hazards of working behind vehicles, trailers, and other equipment being towed on slopes. Employees should be trained on hazard identification, characterization, and avoidance. This training should be provided for newly hired employees and during fresher trainings. Employers should also provide training specific to hazards of new tasks or changes in work procedures.

The employer provided consistent in depth training on how to use, connect, and work around trailers to his employees. However, there was no system or training for workers to identify or distinguish between the different sized trailer hitch balls or the correct size needed. This created a situation where it was possible for employees to use the wrong size trailer hitch ball.

Along with newly developed systems or policies, employers should provide training to current workers at least annually and train new workers before they start any hazardous tasks. Training should emphasize the importance of following SOPs and to continually be on the lookout for potential hazards. In addition to training, employers should reinforce safe work policies and procedures by observing work being done and providing feedback as necessary. 


\section{ACKNOWLEDGEMENTS:}

This report was reviewed by stakeholders from labor and business communities and various Washington State and Federal worker safety agencies. Though we are unable to acknowledge specific individuals for their contributions to this report, we would like to recognize the following for their help and support of the FACE mission and objectives:

- $\quad$ The Employer's representatives involved in the incident

- $\quad$ Division of Occupational Safety and Health (DOSH)

- $\quad$ Federal FACE Program Management (NIOSH)

- $\quad$ Safety \& Health Assessment \& Research for Prevention (SHARP)

\section{REFERENCES:}

1. Prairie Agricultural Machinery Institute, Safe Implement Hitching: A Guide for Safe Connection of Agricultural Tractors to Implements, Prairie Agricultural Machinery Institute, Editor. 2011, Humboldt.

2. Texas A\&M University, Agricultural Safety, in TAMU Health and Safety Plan. 2009, Texas A\&M University. pp 13 - 14.

\section{INVESTIGATOR INFORMATION:}

Todd Schoonover has a PhD in Industrial Hygiene from the University of Illinois at Chicago. He is a Certified Industrial Hygienist $(\mathrm{ClH})$ and Certified Safety Professional (CSP). Todd is currently the Principal Investigator for the WA FACE program.

Eric Jalonen has a Master's in Public Health from East Carolina University. He is a Research Investigator with the WA FACE program.

Randy Clark has a BA from The Evergreen State College. He is a Safety and Health Specialist with the WA FACE program.

Christina Rappin has a BAS from The Evergreen State College. She is a Research Investigator with the WA FACE program. 


\section{Washington State FACE Program Information}

The Washington State Fatality Assessment and Control (WA FACE) program is one of many workplace health and safety programs administered by the Washington State Department of Labor \& Industries' Safety \& Health \& Research for Prevention (SHARP) program. It is a research program designed to identify and study fatal occupational injuries. Under a cooperative agreement with the National Institute for Occupational Safety and Health (NIOSH grant\# 5 U60 OH008487-09), WA FACE collects information on occupational fatalities in WA State and targets specific types of fatalities for evaluation. WA FACE investigators evaluate information from multiple sources. Findings are summarized in narrative reports that include recommendations for preventing similar events in the future. These recommendations are distributed to employers, workers, and other organizations interested in promoting workplace safety. NIOSH-funded, statebased FACE programs include: California, lowa, Kentucky, Massachusetts, Michigan, New Jersey, New York, Oregon, and Washington. WA FACE does not determine fault or legal liability associated with a fatal incident. Names of employers, victims and/or witnesses are not included in written investigative reports or other databases to protect the confidentiality of those who voluntarily participate in the program.

Additional information regarding the WA FACE program can be obtained from:

Washington State FACE Program

www.Ini.wa.gov/Safety/Research/FACE/default.asp

PO Box 44330

Olympia, WA 98504-4330

1-888-667-4277 